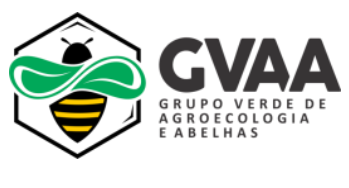

\title{
Cotas rurais no ensino superior público: um panorama analítico
}

\section{Quotas rural employees in public higher education: un analytical panorama}

\author{
Pamela Karina de Melo Gois ${ }^{\left(\mathbb{D}^{1 *}\right.}{ }^{*}$, Ednaldo Barbosa Pereira Junior ${ }^{\left(\mathbb{D}^{2}\right.}{ }^{2}$, Jedson Machado Ximenes ${ }^{\left(\mathbb{D}^{3}\right.}$
}

${ }^{1}$ Mestranda pelo programa Pós-Graduação em sistema Agroindustrial, Universidade Federal de Campina Grande, pamelaufrn@yahoo.com.br; ${ }^{2}$ Professor e Doutor no Instituto Federal da Paraíba, Campus Sousa, ebpjr2@ hotmail.com; ${ }^{3}$ Professor e Doutor no Instituto Federal da Paraíba, Campus Sousa, jedsonmx@ hotmail.com.

\begin{tabular}{l} 
N O T A \\
C IE N T ÍFI C A \\
\hline
\end{tabular}

Recebido: 05/08/2018

Aprovado: 23/03/2019

\section{Palavras-chave: \\ Reserva de vagas \\ Ação afirmativa \\ Estudantes rurais}

\section{R E S U M O}

A Lei de Cotas, além do recorte social, trata de critérios étnico-raciais e permite que as próprias Instituições, a partir da realidade social na qual estão inseridas, utilizem como ação afirmativa a criação de reserva de vagas para beneficiar outros grupos minoritários. O artigo tem como objetivo analisar a política de reserva de vagas para filhos de famílias pronafianas, de assentados da reforma agrária e de empregados rurais no Ensino Superior Público, além de discutir os fundamentos jurídicos desta ação afirmativa, identificando as Instituições Públicas que utilizam esta política de cotas, apresentando os cursos ofertados e o número de vagas reservadas para estes estudantes rurais. Os procedimentos metodológicos da investigação ancoraram-se nos pressupostos da pesquisa qualitativa e quantitativa, de documentação indireta e descritiva. Os resultados da pesquisa indicam que a adoção da Lei de Cotas representou um inegável avanço em relação à democratização, quanto ao acesso a grupos historicamente excluídos previstos na lei. Contudo, ainda são poucas Instituições que utilizam cotas para beneficiar os filhos de famílias pronafianas, de assentados da reforma agrária e de empregados rurais. São apenas 3 em todo o Brasil, os Institutos Federais de Educação, Ciência e Tecnologia da Paraíba, Tocantins e Sudeste de Minas Gerais, ainda assim, em Campi específicos e, em sua maioria, para cursos voltados para a área rural.

\section{A B S T R A C T}

The Quota Law, apart from its social contour, deals with ethnic-racial criteria and allows institutions, based on their particular social reality, to use, as affirmative action, the creation of a reserve of vacancies, aiming at benefitting other minority groups. This article, therefore, aims at analyzing the policy related to the reserving vacancies for children belonging to PRONAF families, settlers of agrarian reform and rural employees who are taking up Public Higher Education. In addition, it aims both at discussing the legal bases concerning this affirmative action, in order to identify the Public Institutions that adopt this quotas policy, and at presenting the offered courses as well as the number of vacancies reserved for rural students. As to its methodological procedure, it was based both on qualitative/ quantitative research, and on indirect and descriptive documentation. The results show that the adoption of the Quotas Law represented an undeniable advance in terms of democratization, taking into consideration the access to the once historically excluded groups. It is important to point out, however, that there are only few institutions adopting such system and benefitting children who belong to PRONAF families, settlers of agrarian reform and rural employees. They are only 3 in Brazil, Federal Institutes of Education, science and technology of Paraíba, Tocantins and southeast of Minas Gerais. Besides, they belong to specific Campuses and are mostly related to courses which are directed to the rural area.

\section{INTRODUÇÃO}

A vida cotidiana e a vida estudantil de crianças e adolescentes em idade escolar nos espaços rurais são bastante duras. A dificuldade em manter, minimamente, um padrão de vida digno em locais onde a alimentação, a higiene, o transporte e a moradia são precários, aliado à dificuldade de continuar na escola, tornam ainda mais penosas as trajetórias desses jovens para obtenção de estudos superiores. Assim, a criação de ações afirmativas que visem beneficiar os estudantes rurais, sejam eles de famílias assistidas pelo Programa Nacional de

\section{Revista Verde}

ISSN 1981-8203

Pombal, Paraíba, Brasil v. 14, n.3, jul.-set, p.464-469, 2019

doi: $10.18378 /$ rvads.v14i2.5891 
Fortalecimento da Agricultura Familiar (PRONAF), de assentados da reforma agrária e/ou de empregados rurais, apresenta-se como um instrumento de efetivação da cidadania. Esta política pública possibilita o acesso destes segmentos historicamente discriminados e que não dispõem de condições materiais idênticas a de seus concorrentes ao Ensino Superior Público.

Em 2012 foi aprovada a primeira lei federal que trata sobre ações afirmativas para o ingresso nas Universidades Federais e nas Instituições Federais, a Lei $\mathrm{n}^{\circ}$ 12.771/12 (BRASIL, 2012a). Até a aprovação desta lei, chamada de Lei de Cotas, as ações afirmativas de cotas se disseminaram pelo país de forma heterogênea, a partir de iniciativas locais, por meio de leis estaduais e deliberações de conselhos universitários das Instituições de Ensino. Este instrumento jurídico, portanto, unificou e formalizou o sistema de reserva de vagas no Ensino Superior Público Brasileiro ao instituir que 50\% das vagas, em Instituições Federais de Educação Superior e de Ensino Técnico, de Nível Médio, deverão ser reservadas aos estudantes de escolas públicas, dentre essas, $50 \%$ reservadas aos estudantes oriundos de famílias com renda de até 1,5 salário-mínimo per capita. Bem como, determina que essas vagas supracitadas deverão ser preenchidas, por curso e turno, por autodeclarados pretos, pardos e indígenas e por pessoas com deficiência, em proporção ao total de vagas no mínimo igual à proporção respectiva de pretos, pardos, indígenas e pessoas com deficiência na população da unidade da Federação onde está instalada a Instituição, a partir de dados do último censo da Fundação Instituto Brasileiro de Geografia e Estatística - IBGE (BRASIL, 2012a).

Conforme o artigo $7^{\circ}$ da Lei de Cotas, a obrigatoriedade de reserva de vagas não existirá indefinidamente, pois este dispositivo determina que no prazo de dez anos, a contar da data de publicação da lei, seja promovida a avaliação da necessidade de continuação desta política pública (BRASIL, 2012a), ou seja, no ano de 2022. Assim, esta medida ostenta o pressuposto da temporariedade, pois apresenta prazo de avalição e a possibilidade de extinção caso seja corrigido o desajuste social que lhe deu causa - o preconceito e a discriminação sofridos pelas minorias - que dificultam o acesso ao Ensino Superior Público.

Além dessas cotas previstas na lei, a Portaria Normativa $\mathrm{n}^{\circ}$ 18/2012 do Ministério da Educação (MEC), em seu artigo 12, permite que as Instituições Federais de Ensino possam instituir reserva de vagas suplementares e/ou indicar outra modalidade de cota mediante a estipulação de vagas específicas para atender políticas de ações afirmativas das próprias Instituições (BRASIL, 2012b). São as chamadas cotas institucionais. Assim, mediante a autonomia que as Universidades Federais possuem, estas podem, desde que cumprido o mínimo legal de aplicação das vagas, instituir reservas de vagas conforme a realidade social dos locais que estão inseridas.

A autonomia universitária é constitucional, prevista no artigo 207, o qual preleciona que "as Universidades gozam de autonomia didático-científica, administrativa e de gestão financeira e patrimonial, e obedecerão ao princípio de indissociabilidade entre ensino, pesquisa e extensão" (BRASIL, 1988). Além disso, a Carta Magna ao designar, em seu artigo 23, as competências comuns da União, dos Estados, do Distrito
Federal e dos Municípios, estabelece no inciso X, a competência de combater as causas da pobreza e os fatores de marginalização, promovendo a integração social dos setores desfavorecidos (BRASIL, 1988), o que justificaria a criação de reserva de vagas a outras minorias não contempladas pela Lei de Cotas, mas que também estão na situação de visível desvantagem de acesso ao Ensino Superior.

Dentre a gama de ações afirmativas institucionais, quanto aos estudantes rurais, Silva e Lage (2011) encontraram em seu trabalho uma iniciativa da Universidade Federal de Goiás que beneficiava os assentados da reforma agrária, porém, na época, foi tida como inconstitucional. Atualmente, a cota para estudantes do meio rural engloba os filhos de pronafianos, de assentados da reforma agrária e de empregados rurais.

Assim, devido à temporalidade da Lei de Cotas, à notória dificuldade de acesso de estudantes rurais ao Ensino Superior e à possibilidade de criação de cotas institucionais que beneficiem os filhos de famílias pronafianas, de assentados da reforma agrária e de empregados rurais, é imprescindível que se trate academicamente este tipo de cota, pois pelo desconhecimento da população acerca desta ação afirmativa e a falta e/ou pouca divulgação da possibilidade de ingresso no Ensino Superior Público por este sistema de cotas, pode-se não atingir o objetivo socialmente esperado: resgatar a dignidade da pessoa humana, seja pela inserção do cidadão no mercado de trabalho ou pela sua manutenção economicamente sustentável no meio rural, por ter tido oportunidade de estudar.

Em face do exposto, o objetivo central deste artigo consiste em analisar a política de reserva de vagas para filhos de famílias pronafianas, de assentados da reforma agrária e de empregados rurais no Ensino Superior Público, além de discutir os fundamentos jurídicos desta ação afirmativa, identificando as Instituições Públicas que utilizam esta política de cotas, apresentando os cursos ofertados e o número de vagas reservadas para estes estudantes rurais.

\section{MATERIAL E MÉTODOS}

Trata-se de uma pesquisa com natureza qualitativa e quantitativa, pois além de utilizar fontes estatísticas sobre a quantidade de Instituições Públicas de Ensino Superior (IPES) que utilizam esta política de cotas, os cursos ofertados e o número de vagas disponíveis para esta cota rural, foram analisados documentos que possibilitaram a obtenção de subsídios teóricos para a ampliação do entendimento de conceitos e definições como, ação afirmativa, políticas públicas, cotas, beneficiários.

Foi utilizada a técnica da pesquisa indireta, que consiste de pesquisa bibliográfica e documental, realizada entre janeiro e maio de 2018, por meio de consultas a livros, artigos publicados em sítios da internet e periódicos, monografias, dissertações, teses, leis, jurisprudências, portarias, resoluções, editais de processos seletivos, termos de adesão ao Sistema de Seleção Unificada (SISU), entre outros, a fim de compreender o funcionamento, os fundamentos jurídicos e os determinantes sociais para a efetivação da política de cotas nas Instituições que a implementam.

É uma pesquisa descritiva, uma vez que teve como objetivo "a descrição das características de determinada 
população ou fenômenos" (GIL, 2010, p. 27), pois visa analisar a política de reserva de vagas para filhos de famílias pronafianas, de assentados da reforma agrária e de empregados rurais no Ensino Superior Público Brasileiro.

Como meio adequado para garantir a objetividade e precisão neste estudo, foi utilizado o método histórico, o qual colocou os dados da pesquisa sobre uma perspectiva histórica, através da comparação de informações anteriores que eram precursoras do que há na atualidade sobre o tema de cotas (MARCONI; LAKATOS, 2010).

Buscou-se contextualizar a política brasileira de cotas de acesso ao Ensino Superior Público para estudantes rurais, identificando as Instituições, os cursos e a quantidade de vagas que se enquadram neste singular programa de cotas.

\section{RESULTADOS E DISCUSSÃO}

\section{Acesso ao ensino superior}

Visando analisar a política de reserva de vagas para filhos de famílias pronafianas, de assentados da reforma agrária e de empregados rurais e tendo em vista que os processos seletivos para admissão nas Instituições Públicas de Ensino Superior podem ser pelo SISU e/ou através de seleção própria da
Universidade, buscou-se examinar tanto os termos de adesão do SISU quanto os editais dos processos seletivos das Instituições.

No SISU para o primeiro semestre de 2018 foram disponibilizadas 239.601 vagas para 4.206 cursos, distribuídas entre 130 Instituições Públicas de Ensino Superior: 30 Estaduais e 100 Federais. Destas, 61 eram Universidades Federais, 36 Institutos Federais de Educação, Ciência e Tecnologia, 2 Centros Federais de Educação Tecnológica e 1 Faculdade.

Observou-se que todas as Universidades Federais, Universidades Estaduais, Institutos Federais de Educação, Ciência e Tecnologia e Centros Federais de Educação Tecnológica participantes do SISU reservaram vagas para estudantes que cursaram o ensino médio em escolas públicas, isto é, reservaram vagas para os beneficiários obrigatórios previstos na Lei de Cotas.

O quadro 1 apresenta as Instituições Públicas de Ensino Superior (IPES) que adotaram, para o $1^{\circ}$ semestre de 2018, ação afirmativa de acesso ao Ensino Superior Público para filhos de pronafianos, de empregados rurais e/ou de assentados da reforma agrária. Dentre as 130 Instituições que participaram da $1^{\text {a }}$ edição do SISU de 2018, apenas 3 utilizam esta cota institucional, todas são Instituições Federais, e ainda assim, em Campi específicos, isto é, não englobando toda a Instituição de Ensino.

Quadro 1. Instituições Públicas de Ensino Superior que adotaram, para o $1^{\circ}$ semestre de 2018, ação afirmativa para filhos de pronafianos, de empregados rurais e/ou de assentados da reforma agrária.

\begin{tabular}{|c|c|c|c|c|}
\hline $\begin{array}{c}\text { Nome da Instituição de } \\
\text { Ensino }\end{array}$ & Campus & \multicolumn{1}{|c|}{ Beneficiários } & $\begin{array}{c}\text { Formas de } \\
\text { ingresso }\end{array}$ \\
\hline $\begin{array}{c}\text { Instituto Federal da } \\
\text { Paraíba (IFPB) }\end{array}$ & Sousa & $\begin{array}{l}\text { filhos de famílias pronafianas ou filhos de } \\
\text { empregados rurais ou filhos de assentados da } \\
\text { Reforma Agrária }\end{array}$ & Cotas & SISU \\
\hline $\begin{array}{c}\text { Instituto Federal do } \\
\text { Sudeste de Minas Gerais } \\
\text { (IFSEMG) }\end{array}$ & Rio pomba & $\begin{array}{l}\text { filho/membro de famílias pronafianas ou } \\
\text { empregado rural ou filho de empregados rurais } \\
\text { ou filho/membro de assentados da reforma } \\
\text { agrária }\end{array}$ & $\begin{array}{c}\text { Cotas } \\
\text { próprio e SISU }\end{array}$ \\
\hline $\begin{array}{c}\text { Instituto Federal do } \\
\text { Tocantins (IFTO) }\end{array}$ & Aarbacena & Assentados da reforma agrária & Cotas & SISU \\
\hline
\end{tabular}

Quanto aos beneficiários, tanto o IFSEMG quanto o IFPB disponibilizaram cotas para filhos de pronafianos, de empregados rurais ou de assentados da reforma agrária, já o IFTO restringe sua cota aos assentados da reforma agrária. Percebe-se que o IFSEMG utiliza o termo "filho/membro" para os beneficiários, tornando esta cota ainda mais abrangente, pois contempla tanto os filhos quanto qualquer outro membro das famílias descritas.

Observa-se que todas as Instituições acima utilizaram as cotas como tipo de ação afirmativa, sendo assim, a competição pelas vagas reservadas se deu apenas entre os beneficiários, já que, segundo Silva e Lage (2011), as modalidades de ações afirmativas operadas nas Universidades podem ser: cotas, bônus e/ou acréscimo de vagas. As cotas consistem nas reservas de vagas, estabelecendo uma porcentagem ou uma quantidade fixa de vagas no total de vagas oferecidas. $\mathrm{O}$ bônus é o acréscimo de pontos ou notas no vestibular tradicional para um dado segmento. Já o acréscimo de vagas, como o próprio nome sugere, consiste na criação de novas vagas para contemplar um determinado grupo.

Quanto ao procedimento de admissão, o SISU foi a forma de ingresso empregada por todas as Instituições, no entanto, o IFSEMG também aplicou processo seletivo próprio (ver quadro 1).

\section{Cursos ofertados pelas Instituições Públicas de Ensino Superior}

Ao analisar os cursos ofertados com cotas para estudantes rurais, conforme expresso no quadro 2, percebe-se como são limitadas as opções de curso para os beneficiários desta cota, pois dos 4.206 cursos ofertados, apenas 10 possuem a previsão desta reserva de vaga. Não obstante, verifica-se que as IPES disponibilizam as cotas, em sua maioria, para cursos voltados para o meio rural: agronomia, agroecologia, zootecnia, alimentos, laticínios e medicina veterinária. 
Quadro 2. Cursos ofertados para os filhos de pronafianos, de empregados rurais e/ou de assentados da reforma agrária nas edições do SISU entre os anos de 2013 e 2018.1 nas Instituições de Ensino Superior e o número de vagas reservadas, por curso, na $1^{\text {a }}$ edição do SISU de 2018.

\begin{tabular}{|c|c|c|c|}
\hline $\begin{array}{l}\text { Instituiçõos de } \\
\text { Ensino Superior }\end{array}$ & Campus & Cursos & $\begin{array}{l}\text { Número de vagas em } \\
2018.1 \text { (por curso) }\end{array}$ \\
\hline IFPB & Sousa & $\begin{array}{c}\text { Agroecologia } \\
\text { Alimentos } \\
\text { Educação Física (Licenciatura) } \\
\text { Medicina Veterinária } \\
\text { Química (Licenciatura) }\end{array}$ & $\begin{array}{c}2 \text { vagas reservadas em } 30 \\
\text { ofertadas } \\
(6,6 \%)\end{array}$ \\
\hline \multirow[t]{2}{*}{ IFSEMG } & Barbacena & $\begin{array}{c}\text { Agronomia } \\
\text { Tecnologia de Alimentos }\end{array}$ & $\begin{array}{l}1 \text { vaga reservada em } 20 \\
\text { ofertadas }(5 \%)\end{array}$ \\
\hline & Rio Pomba & $\begin{array}{c}\text { Agroecologia } \\
\text { Zootecnia } \\
\text { Ciência e Técnica de Alimentos } \\
\text { Ciência e Técnica de Laticínios }\end{array}$ & $\begin{array}{c}1 \text { vaga reservada em } 20 \\
\text { ofertadas }(5 \%)\end{array}$ \\
\hline \multirow[t]{2}{*}{ IFTO } & Araguatis & $\begin{array}{c}\text { Agronomia } \\
\text { Computação (Licenciatura) } \\
\text { Ciências Biológicas (Licenciatura) }\end{array}$ & $\begin{array}{c}1 \text { vaga reservada em } 20 \\
\text { ofertadas }(5 \%)\end{array}$ \\
\hline & $\begin{array}{l}\text { Colinas do } \\
\text { Tocantins }\end{array}$ & Computação (Licenciatura) & - \\
\hline
\end{tabular}

Em estudo realizado por Muller (2016), sobre as perspectivas das jovens rurais que estudam na Universidade Federal da Fronteira Sul (UFFS) - Campus Realeza - PR, em relação à permanência no espaço rural, a autora encontrou que entre as jovens rurais há o objetivo de se qualificar para ingressar no mercado de trabalho não agrícola, não querendo permanecer no espaço rural. Assim, ter cotas para estudantes rurais apenas em cursos voltados para a área rural pode não ser atrativo para estes estudantes, bem como, impossibilita aos jovens que não desejam permanecer no espaço rural acessarem o mercado de trabalho urbano de forma mais qualificada.

Esta limitação de possibilidades de graduação para os estudantes rurais fica bem evidente no IFSEMG, pois no Campus de Barbacena, são ofertados 10 cursos: agronomia, tecnologia de alimentos, administração, ciências biológicas, educação física, gestão ambiental, gestão de turismo, nutrição, química e sistemas para internet. Desses, apenas os dois primeiros têm vagas reservadas para estudantes rurais. O mesmo acontece no Campus Rio Pomba, dos 8 cursos que possui - agroecologia, zootecnia, ciência e técnica de alimentos, ciência e técnica de laticínios, administração, ciência da computação, educação física e matemática - apenas 4 utilizam a estudada cota. No IFPB e no IFTO não há essa distinção, nos Campi que fazem uso da cota, todos os cursos ofertados preveem reserva de vagas.

Ainda no quadro 2, estão representadas as quantidades de vagas reservadas dentre as vagas ofertadas em cada curso, por Campus, na $1^{\text {a }}$ edição do SISU de 2018. Assim, percebe-se o IFSEMG e o IFTO reservam 5\% das vagas para os filhos de pronafianos, de empregados rurais e/ou de assentados da reforma agrária. Já o IFPB utiliza a proporção de 6,6\%.

Apesar de ainda serem poucas vagas, a utilização de cotas pelas Instituições Públicas de Ensino Superior situadas próximas ao meio rural com reservas de vagas para os filhos de famílias pronafianas, de assentados da reforma agrária e de empregados rurais representa uma iniciativa para a reparação histórica desses grupos excluídos, pois, segundo Castro (2016, p. 67), "as Universidades são consideradas o principal instrumento de ascensão social".

\section{Distribuição de vagas entre 2013 e 2018}

Buscando analisar a trajetória da política de reserva de vagas para filhos de pronafianos, de empregados rurais e/ou de assentados da reforma agrária após a aprovação da a Lei $\mathrm{n}^{\circ}$ 12.771/12, o quadro 3 apresenta a distribuição da reserva de vagas ofertadas a partir de 2013 para os cursos presenciais das Instituições Públicas de Ensino Superior que utilizam a estudada cota. Primeiramente, pode-se constatar que esta cota institucional não é constante, pois em alguns anos desse período ela deixou de ser adotada em duas Instituições. $O$ fato de ser um ato discricionário da gestão e não uma imposição legal pode explicar esta inconstância. Heringer (2014, p. 22) destacou a preocupação sobre sua continuidade ao longo do tempo pela falta de previsão legal afirmando que: "as decisões se baseiam principalmente em normas aprovadas pelos conselhos universitários ou órgãos superiores equivalentes nas universidades, ficariam, portanto, mais sujeitos às mudanças conjunturais de ordem política dentro de cada Instituição".

Percebe-se também no quadro 3 uma ampliação dos indivíduos beneficiários no IFPB-Campus Sousa, pois em 2013, a cota institucional só contemplava os assentados da reforma agrária, mas a partir de 2014, esta foi estendida aos filhos de famílias pronafianas e filhos de empregados rurais.

Outro dado interessante é a quantidade de vagas que foram distribuídas pelos programas de ação afirmativa nas 3 Instituições que adotam esta modalidade de cotas. Para o $1^{\circ}$ semestre de 2018 foram reservadas 25 vagas para estes estudantes rurais, dessas vagas, 19 foram ofertadas mediante o SISU e 6 por processo seletivo próprio. Assim, das 239.601 vagas disponibilizadas pela $1^{\text {a }}$ edição do SISU de 2018 e, das 17.369 vagas provenientes de políticas de ação afirmativa 
próprias das Instituições, apenas 19 vagas foram reservadas para os filhos de pronafianos, de empregados rurais e/ou de assentados da reforma agrária, o que representa apenas $0,1 \%$ das vagas utilizadas como ação afirmativa. Um valor muito baixo diante do número de famílias participantes do PRONAF, de empregados rurais e de assentados da reforma agrária no Brasil. Dados recentes divulgados pelo Instituto Nacional de Colonização e Reforma Agrária (INCRA) indicam que existem hoje no Brasil quase um milhão de famílias assentadas em mais de nove mil assentamentos. A última atualização dos dados, que ocorreu em 31/12/2017, apresenta que o país possui 972.289 famílias assentadas e 9.374 assentamentos (INCRA, 2017). Quanto ao PRONAF, segundo dados do Censo Agropecuário de 2006, $84,4 \%$ do total dos estabelecimentos agropecuários brasileiros pertencem a grupos familiares. Eram 4.366.267 de estabelecimentos de agricultores familiares, sendo que a metade deles está na Região Nordeste (IBGE, 2006).

Quadro 3. Distribuição do número de vagas reservadas para os filhos de pronafianos, de empregados rurais e/ou de assentados da reforma agrária em cursos de graduação presencial ofertados pelas IPES nos anos de 2013 a 2018 ( ${ }^{\circ}$ semestre).

\begin{tabular}{|c|c|c|c|c|c|c|c|}
\hline \multirow{2}{*}{$\begin{array}{l}\text { Instituições de Ensino } \\
\text { Superior }\end{array}$} & \multirow[t]{2}{*}{ Campus } & \multicolumn{6}{|c|}{ ANO } \\
\hline & & 2013 & 2014 & 2015 & 2016 & 2017 & 2018 \\
\hline IFPB & Sousa & $6^{*}$ & 15 & 3 & 10 & 10 & 10 \\
\hline \multirow[t]{2}{*}{ IFSEMG } & Barbacena & - & - & 4 & 4 & 4 & 4 \\
\hline & Rio Pomba & 2 & - & 8 & 12 & 8 & 8 \\
\hline \multirow[t]{2}{*}{ IFTO } & Araguatis & $3 *$ & - & - & - & $2 *$ & $3 *$ \\
\hline & Colinas do Tocantins & - & - & - & - & $3^{*}$ & - \\
\hline \multicolumn{2}{|c|}{ Total de vagas } & 11 & 15 & 15 & 26 & 27 & 25 \\
\hline
\end{tabular}

* apenas para assentados da reforma agrária

O fato de apenas 3 IPES aderirem à cota para estudantes rurais, bem como a pequena quantidade de vagas destinadas a esta cota demonstram uma falta de integração entre as Instituições Públicas com o foco na correção das distorções sociais existentes no meio rural, pois, é notório que a desigualdade combatida por esta cota não existe em apenas quatro ou cinco municípios brasileiros.

Para Daflon et al. (2013), algumas desvantagens da falta de integração entre essas iniciativas, vão desde a dificuldade de publicizar essas medidas para os potenciais beneficiários, a ausência de critérios claros e de comum conhecimento para a fruição do benefício, até problemas concernentes à concepção, planejamento e execução das políticas.

Em estudo realizado por Fernandes (2014) sobre a percepção das ações afirmativas nas Universidades Federais, entre os aspectos negativos, encontrou que o sistema é pouco divulgado, permitindo com que os próprios participantes do sistema não saibam, de fato, como funcionam. Essa falta de informação tanto no meio acadêmico quanto na comunidade em geral, priva diversas pessoas de usarem o sistema, logo o seu objetivo não é plenamente alcançado.

A partir desses dados, percebe-se a importância de políticas públicas que busquem reverter, no âmbito universitário, o quadro histórico de desigualdade e de desvantagem na concorrência entre estudantes urbanos e rurais. Mais especificamente em relação à educação, tornam-se urgentes medidas que corrijam as desigualdades de acesso e de manutenção do contingente de alunos de áreas rurais nas Universidades brasileiras, seja em um contexto mais amplo das ações afirmativas, seja em um âmbito mais restrito das cotas para estudantes rurais. Pois, conforme afirmam Ferreira e Chicanato (2010, p. 6): "é justa e aceitável a realização das ações afirmativas ao priorizar grupos excluídos, de maneira que as minorias se aproximem do mínimo democrático e ideal, a fim de que no futuro exista justiça social".

\section{CONCLUSÃO}

A ação das cotas têm na sua essência, a ânsia pela efetivação dos direitos humanos, dignos de todo ser humano. Com a reserva de vaga para estudantes rurais, é possível que ocorra a efetiva inclusão social deste grupo e a modificação de seu quadro econômico-social. Portanto, tendo em vista a notória desvantagem na concorrência entre estudantes urbanos e rurais, ainda são poucas as Instituições Públicas de Ensino Superior que utilizam esta cota institucional, apenas 3 em todo o Brasil, os Institutos Federais de Educação, Ciência e Tecnologia da Paraíba, Tocantins e Sudeste de Minas Gerais, ainda assim, em Campi específicos. Demonstrando a falta de um olhar para outras minorias, diferentes das impostas pela Lei de Cotas.

Além de poucas vagas para os filhos de pronafianos, de empregados rurais e/ou de assentados da reforma agrária, que no $1^{\circ}$ semestre de 2018 contabilizou apenas 25 vagas para estes estudantes rurais, contata-se que existe uma distinção de cursos ofertados para esta cota em alguns Campi, gerando uma limitação do campo de trabalho ao disponibilizar apenas opções de formação superior para o labor no espaço rural ou associado a ele.

O pouco interesse dos Instituições Públicas de Ensino Superior na reserva de vagas para os filhos de pronafianos, de empregados rurais e/ou de assentados da reforma agrária, juntamente com a falta de divulgação e a temporalidade da Lei de Cotas prejudicam os fins maiores desta ação afirmativa: a democratização do acesso ao Ensino Superior, a dessegregação do espaço universitário e a efetivação da cidadania para os estudantes rurais.

\section{REFERÊNCIAS}

BRASIL. Constituição (1988). Constituição da República Federativa do Brasil: promulgada em 5 de outubro de 1988. Obra coletiva de autoria da Editora Saraiva com a colaboração 
de Antonio Luiz de Toledo Pinto, Márcia Cristina Vaz dos Santos Windt e Livia Céspedes.- 44. ed. atual. e ampl.- São Paulo: Saraiva, 2010. 314p.

BRASIL. Lei $n^{\circ} 12.711$ de 29 de agosto de 2012. Dispõe sobre o ingresso nas universidades federais e nas instituições federais de ensino técnico de nível médio e dá outras providências. 2012a.

BRASIL. Portaria Normativa $n^{\circ} 18$ de 11 de outubro de 2012. Dispõe sobre a implementação das reservas de vagas em instituições federais de ensino de que tratam a Lei n. 12.711, de 29 de agosto de 2012, e o Decreto n. 7.824, de 11 de outubro de 2012. 2012b.

CASTRO, F. G. Política de cotas no Instituto Federal de Educação, Ciência e Tecnologia do Tocantins - Campus Gurupi: reflexos da lei $\mathrm{n}^{\mathrm{o}} 12.711$, de 29 de agosto de 2012. Palmas: UFTO, 2016. 204 p.

DAFLON, V. T.; FERES JÚNIOR, J.; CAMPOS, L. A. Ações afirmativas raciais no ensino superior público brasileiro: um panorama analítico. Cad. Pesquisa, São Paulo, v.43, p.302-327, 2013. http://dx.doi.org/10.1590/S0100-15742013000100015.

FERNANDES, G. F. Percepção das ações afirmativas nas universidades federais: os casos da UFRGS e UNIPAMPA. Santana do Livramento: UNIPAMPA, 2014. 19 p.

FERREIRA, D. S. I; CHICANATO, D. J. Ações afirmativas e a política de cotas raciais dentro do sistema educacional brasileiro. Revista Processus de Estudos de Gestão, Jurídicos e Financeiros, Brasília, ano 1, v.2, 2010.

GIL, A. C. Como elaborar projetos de pesquisa. 5. ed. São Paulo: Atlas, 2010. 184 p.

HERINGER. R. Um Balanço de 10 Anos de políticas de ação afirmativa no Brasil. Revista do Programa de Pós-graduação em Sociologia da Universidade Federal de Sergipe, Alagoas, v. 24, p.210-227,

2014.

IBGE. Censo agropecuário 2006. Disponível em: <https://www.ibge.gov.br/estatisticasnovoportal/economicas/agricultura-e-pecuaria/9827-censoagropecuario.html?edicao $=9829 \& \mathrm{t}=$ publicacoes $>$

INCRA. Informações gerais sobre os assentamentos da reforma agrária. 2017. Disponível em: <http://painel.incra.gov.br/sistemas/index.php>

MARCONI, M. A; LAKATOS, E. M. Fundamentos de metodologia científica. 7.ed. São Paulo: Atlas, 2010. 286 p.

MULLER, M. P. As jovens rurais e as perspectivas de permanência no espaço rural: um estudo de caso no Campus Realeza da Universidade Federal da Fronteira do Sul. Francisco Beltrão: UNIOESTE, 2016. 158p.
SILVA, I. G; LAJE, T. Direito social à educação: acesso ao ensino superior - o debate sobre as políticas de ações afirmativas nas Universidades Públicas Brasileiras. Rio de Janeiro: PUC, 2011. 40 p. 